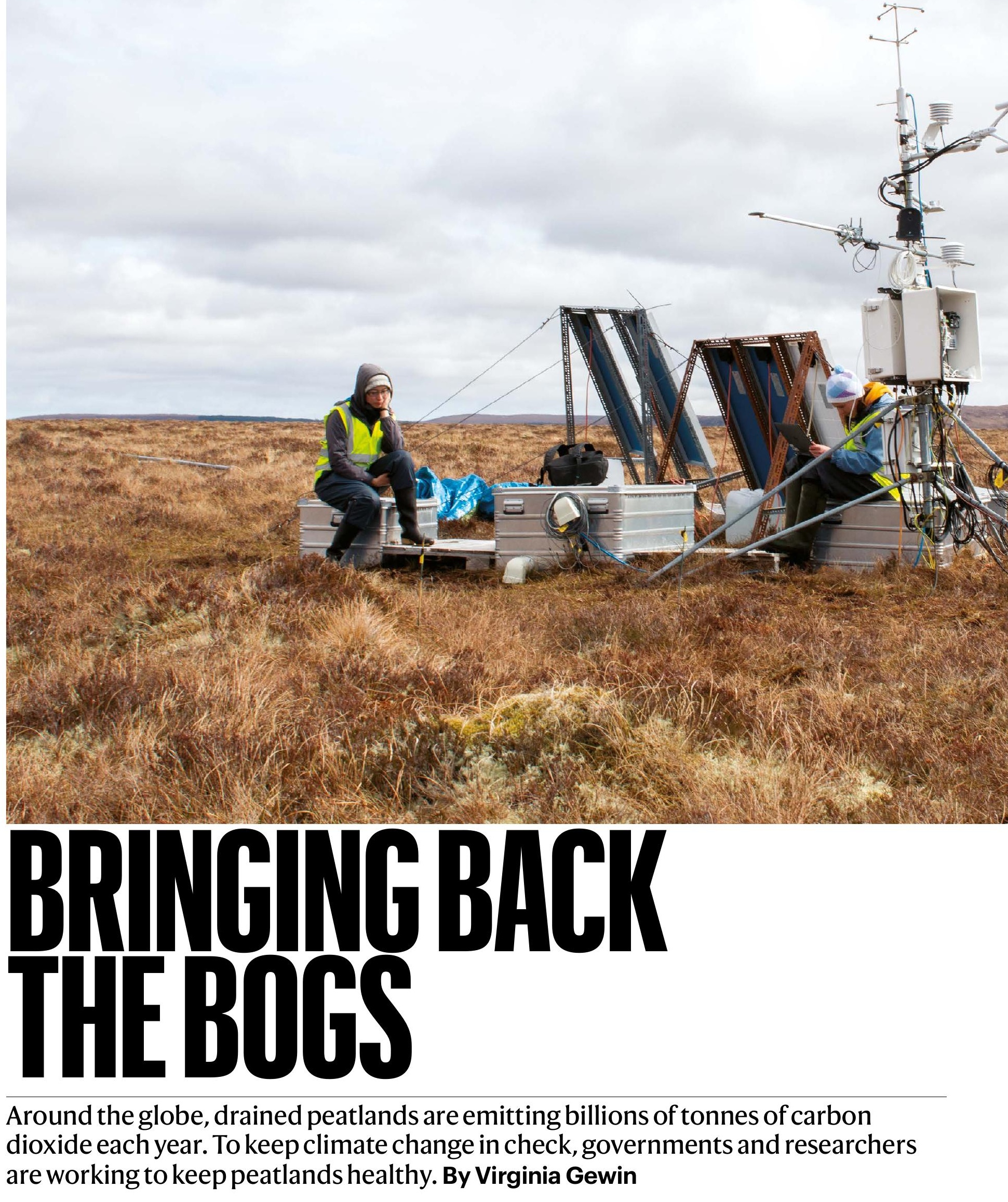


A flux tower in Scotland's Flow Country measures gas concentrations and other variables in a peatland.

they lock up vast amounts of carbon. If they are not kept healthy, the bogs could release their stored carbon and accelerate global warming.

That's why a team of researchers and land managers is digging up trees and flattening furrows in former plantations southwest of Thurso. The effort is part of a roughly £50-million (US\$65-millon) investment that the Scottish government and other organizations have made towards restoring the country's blanket bogs - undulating carpets of spongy hummocks built from Sphagnum mosses. The largest area of blanket bogs in the world is in the Flow Country - a low-lying expanse between sheer cliffs to the north and glacially carved mountains to the southwest.

Remote and exposed, these peatlands are named after the Norse term floi, which means boggy ground. They have long been described as worthless wastelands. "Local people called the peatlands mamba-miles and miles of bugger all," says Roxane Andersen, a biogeochemist at the University of the Highlands and Islands' Environmental Research Institute in Thurso.

More than $80 \%$ of the 1.7 million hectares of peatland in Scotland have been cut for fuel or otherwise degraded, and roughly 500,000 hectares have been drained and forested with non-native conifers. "The reality, though, is the trees did poorly," says Andersen.

Despite that, the peatlands have tremendous value for carbon storage. These areas hold more than one-quarter of all soil carbon, even though they account for only 3\% of Earth's land area $^{1}$. Globally, peatlands hold more than twice as much carbon as the world's forests do, according to the United Nations Environment Programme.

But in many places, humans have turned vast expanses of these environments from long-term carbon sinks into carbon sources. Damaged or drained peatlands worldwide emit at least 2 billion tonnes of carbon dioxide annually - roughly $5 \%$ of anthropogenic greenhouse-gas emissions - largely through peat fires and oxidation of the buried carbon. And emissions from bogs are expected to rise sharply.

As the threat of climate change has grown more severe, researchers and governments have identified peatlands as ideal targets for stopping emissions, and even sopping up carbon. Although Canada, Russia and Indonesia contain the largest tracts of peatland in the world, Scotland has emerged as a leader in the effort to restore the habitat, which covers more than $20 \%$ of the country (see 'For peat's sake'). Scotland will probably meet, if not exceed, its 2020 goal of restoring 50,000 hectares, mainly on government-owned nature reserves and forestry land. And it aims to push that total to 250,000 hectares by 2030 .

Restoring peatlands to health is one of the key ways in which Scotland, which last April became the first country to declare a climate emergency, intends to reach net-zero greenhouse-gas emissions by 2045. "Scotland has raced out in front by making good connections with researchers and government," says Jack Rieley, a tropical-peatland ecologist and executive board member of the International Peatland Society, which is based in Jyväskylä, Finland. Researchers from around the world have flocked to Scotland to glean insights into how to develop a successful national strategy for restoring peatland.

The biggest question is whether restoration will simply stop carbon emissions from peatlands or revive the bogs to the point that they can store more carbon. Other countries, notably Indonesia, are also pursuing efforts to reduce carbon losses from their peatlands. To make sure that these projects are working, researchers are developing satellite techniques and other tools to monitor the health of these landscapes.

But there is no guarantee that the efforts will pay off. "It's so easy to break an ecosystem, and it's so hard to bring it back," says Andersen. "We can't recreate something from the past, but we can do our best to make it resilient."

\section{Tough going}

Just over 100 kilometres southwest of Thurso, the boggy soil is so sodden in spots that I sink up to my knees and nearly lose a boot. But the muck hasn't stopped two excavators - each more than 13 tonnes - that are fitted with

\section{"It's so easy to break an ecosystem, and it's so hard to bring it back."}

extra-wide tracks to distribute their weight. As part of an effort to convert the region back to bogs, they trundle across the peat, cutting and stacking stands of trees that have been there for 30 years.

The timber is low quality, pockmarked by hungry pests and prone to being blown down, a hallmark of trees that are growing in acidic peat. Neil McInnes and Tim Cockerill oversee this and other restoration projects undertaken by Forestry and Land Scotland, a government land-management agency based in Inverness. The harvest costs more than the timber is worth, and because the trees will be either incinerated on site to generate electricity or made into heating pellets, the carbon in the trees will return to the atmosphere.

Removing the trees was a bitter pill at first. Many foresters felt they were being unfairly ers and the Scottish government started to see the peatlands in a fresh light, recognizing that 
criticized for having planted them in the first place - even though it had been a government directive at the time. But McInnes says that attitudes have changed over the past few years as people have grown to understand the carbon-storage potential of peatlands, and the Scottish government has made it a priority to reduce emissions. “It doesn't feel like a fight any more," he says.

Early peatland-restoration efforts began in Flow Country in 1995 , focused more on restoring bird habitats. "Carbon was barely on the agenda at that time," says Norrie Russell, former manager of the Forsinard Flows reserve, which is owned by the Royal Society for the Protection of Birds and is where Andersen conducts her research.

The agenda gained momentum in 2010 , when the International Union for Conservation of Nature launched the UK Commission of Inquiry on Peatlands to assess the state of these ecosystems. That effort - along with widespread support for tackling climate change - triggered more interest in nursing peatlands back to health. Now, Russell says, the political push for peatland restoration is focused mainly on keeping carbon locked up. In a 2017 public survey (see go.nature.com/2sfvbiy), the vast majority of respondents supported restoration to mitigate climate change, to improve water quality and wildlife habitat and to protect this important aspect of Scotland's identity.

\section{Towers of resilience}

Andersen is working with McInnes and Cockerill, as well as various organizations, to determine how best to manage the land for carbon storage. To gather evidence, she and her colleagues have installed four towers in Flow Country since 2008 to monitor the flow of gases and temperature, among other variables. Sensors near the towers measure heat flux, water level, soil temperature and precipitation. Building on existing data, Andersen won a $£ 986,088$ award last year from the London-based charity the Leverhulme Trust to determine how to make peatland resilient. In the data collected so far, Andersen and her colleagues have detected some promising changes $^{2}$. They found that the first patches of restored peatlands, in which trees were simply cut and rolled into the blocked drainage ditches, switched from a carbon source to a carbon sink after 16 years. Although that work demonstrated that transitioning forest back to bog can be an effective way to restore a carbon sink, the researchers found that they could get faster results with more intensive management - such as clearing the carbon-rich trees and branches and flattening the ground. Although these more intensive strategies can trigger an initial pulse of greenhouse-gas emissions by disturbing the soil, once it is more uniformly wet this can also accelerate the switch

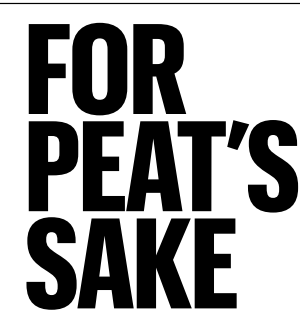

Peatlands hold more than one-quarter of the planet's soil carbon, yet cover just $3 \%$ of the land. These habitats blanket more than $20 \%$ of Scotland, which aims to restore 250,000 hectares by 2030 .

- Deep peat, carbon-rich soils

Shallower peat, mostly carbon-rich soils

- Forest cover

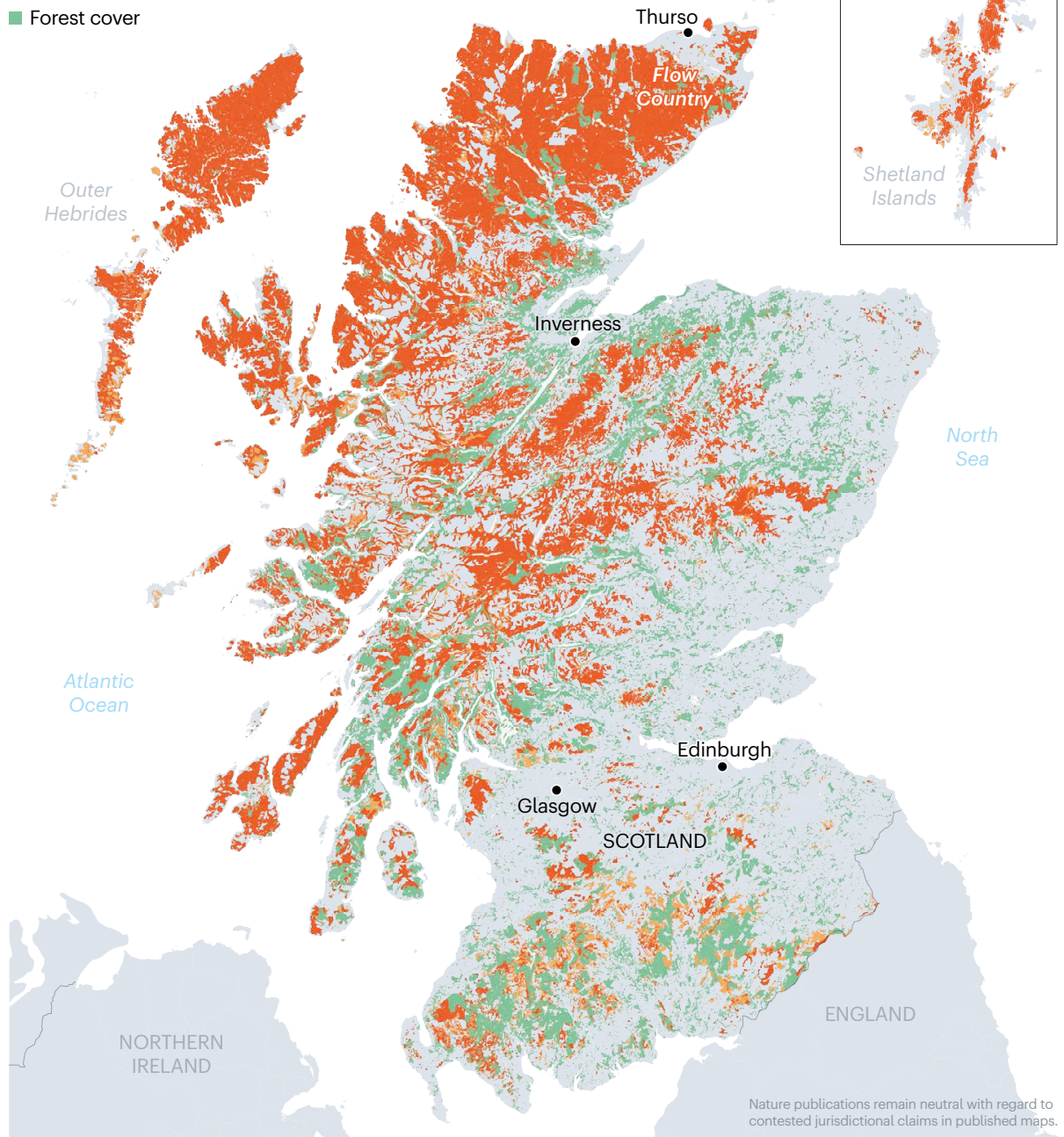

from carbon source to sink - bringing it down to as little as ten years, says Andersen.

These results mirror research in Canada that found it takes one to two decades for peatlands to recover following restoration efforts ${ }^{3}$. The trick to restoring the natural hydrology, the way water moves through the system and is stored by the peat, is choosing locations that aren't too degraded and where there is still enough residual peat and plant vegetation, says Nigel Roulet, a peatland scientist at McGill University in Montreal, Canada. "If you nudge systems along, and pamper them through first years of recovery, they take off on their own," says Roulet, "and carbon dynamics return to a natural system within a decade or two."

But that's a complicated story to convey - especially amid a groundswell of support around the globe for efforts to plant trees to combat global warming. Last year, a study suggested that Earth's ecosystems could support 1 billion more hectares of forest - and store $25 \%$ of the atmospheric carbon pool ${ }^{4}$. Politicians in many countries, including the United Kingdom, have been eagerly promoting efforts to plant more trees. Scotland planted 
11,200 hectares of new woodlands in 2018. And in the run-up to last December's UK general election, both the Labour and Conservative parties promised to plant millions more trees each year. These new arboreal ambitions could make it harder for researchers and officials to argue that peatlands are the wrong places for trees. “Unless landowners and managers all work together on an agreed strategy then there will be pressure," says McInnes. "We've seen this before."

\section{Breathing bogs}

The key question about restoration efforts across the globe is how well they can slow greenhouse-gas emissions from bogs. To answer that, researchers need cheaper and faster tools for assessing the health of peatland over wide areas. Andersen has partnered with geoscientist David Large at the University of Nottingham, UK, to develop a method for monitoring 'bog breathing' through satellite measurements - specifically, interferometric synthetic aperture radar (InSAR). Because peatlands that are functioning well rise and fall with the level of the water table, the carbon emissions can be inferred from how the peat behaves, says Large.

The team tested this method on 22 sites around the Flow Country over 18 months and found that wet, mossy peat in good condition - the least likely to be a carbon source - rises in mid-winter and falls in mid-summer ${ }^{5}$. Drier, shrubby peat, which is more likely to emit carbon, rises in late spring and falls in late summer. As a next step, the researchers plan to correlate their InSAR results with measurements of carbon emissions.

InSAR will offer funders and government officials a means of quantifying success, says Large. "At what point is peat restored? We've spent millions and haven't really thought

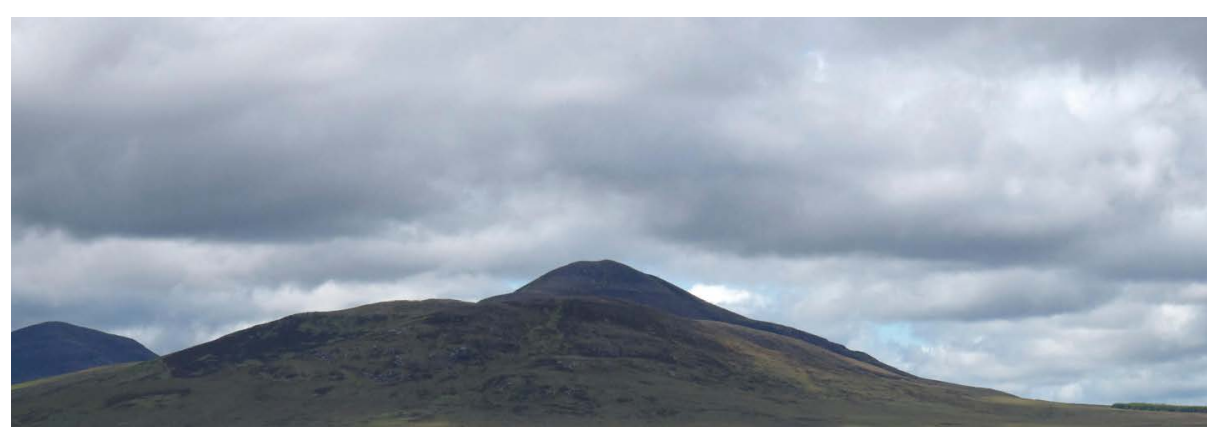

through what success will look like," he says, at least in terms of metrics. Large is now testing the tool in tropical peatlands, which he says are challenging because in areas such as southeast Asia, peat builds only under forest cover, and the trees cause trouble for InSAR. If the methodology can be validated across peatland types and conditions, it could help governments to chose which areas to restore and to monitor how effective interventions have been, says Susan Page at the University of Leicester, UK, who studies peatlands in southeast Asia.

Other teams are developing different methods for monitoring peatland emissions. In the tropics, for example, researchers are tracking deforestation, which often precedes efforts to drain the peatlands. Every country will have to develop its own monitoring system, says Hans Joosten, a peatland ecologist at the University of Greifswald in Germany.

Monitoring is urgently needed in many regions, including Indonesia. The country is plagued by seasonal fires that spread over dry peatlands and send billows of smoke across much of the country. The fire risk has increased in the past few decades because dams were installed to drain the country's peat and grow crops - notably oil palm trees, which do best when the water table is roughly 80 centimetres below the surface. Following devastating peat fires in 2015, Indonesia set an ambitious goal to restore 2 million hectares, about $10 \%$ of the roughly 20 million hectares of the country's original peat swamp forests, by 2020 to prevent fires and improve air quality.

By the end of last year, the campaign has re-wetted about 788,000 hectares, which involves raising the water table to within 40 centimetres of the surface. Nazir Foead, head of Indonesia's Peatland Restoration Agency says investigations in the country found that "when the table fell below 40 centimetres, the fire incidences soar significantly". Indonesia plans to achieve more than half of its carbon-reduction goals to support the Paris climate agreement through re-wetting and protecting peatlands.

In theory, these plans should reduce Indonesia's emissions, but they probably won't restore peat's ability to store new carbon, according to several researchers. "Re-wetting is the initial stage towards peatland restoration but it is not the magic bullet," says Rieley. Unlike in Scotland where mosses build up peat, trees are needed to deposit peat layers in tropical systems. In Indonesia, "where is the peat going to come from?" asks Rieley. Foead says his agency can't yet quantify how many trees have actually been replanted.

Even if Indonesia doesn't turn its peatlands back into a carbon sink, Joosten argues that re-wetting to 40 centimetres below the peat surface will reap big rewards from a climate perspective. Doing so would cut emissions from re-wetted areas by $50 \%$ because it halves 
the amount of peat exposed to oxidizing conditions. And it would reduce global emissions much more than Scotland's endeavours, says Joosten, who was part of an international team that, in 2018, won the Indonesia Peat Prize, which is awarded by the government and the David and Lucile Packard Foundation, based in Los Altos, California. The team devised a method to map the extent and depth of peat.

\section{Rare efforts}

A fundamental problem is that large-scale peatland restoration is happening in just a few locations, say researchers. In fact, the global total peatland area is decreasing because bogs continue to be drained in the tropics and the land is converted for other uses. If that continues, carbon released from peatlands will help to send the global temperature shooting past the target of $1.5-2{ }^{\circ} \mathrm{C}$ warming above pre-industrial levels set by the Paris agreement.

One complication in the effort to re-wet peatlands is that restored wetlands will produce some amount of methane, which is a potent greenhouse gas. But Joosten says that this will be more than balanced by the reduction in emissions of carbon dioxide and nitrous oxide. Overall, re-wetting has a net benefit for the climate. Rather than aiming to turn global peatlands into sinks, he says, a more realistic near-term goal is to make bogs carbon neutral.

Achieving carbon neutrality for peatlands across the globe would have a major impact. Last year, Page and her colleagues found that by 2015 , drained peatlands had emitted about 80 billion tonnes of carbon dioxide - and that this cumulative amount would roughly triple by 2100 (ref. 6). Estimates suggest that nations will need to limit future carbon-dioxide emissions to something on the order of 400 billion to 1,600 billion tonnes to keep temperatures from rising above the Paris target. But peatlands are on track to account for roughly $10-40 \%$ of that budget, unless countries take steps to protect and restore these environments, according to Page and her colleagues.

To keep that from happening, says Joosten, "all drained peatlands in the world have to be re-wetted. No cherry-picking which are easiest, cheapest or most effective any more". Indeed, the United Nations Environment Assembly adopted its first ever peatland resolution last year, urging member states to conserve and restore these carbon-rich ecosystems.

Still, researchers say it will be important to document how much carbon is lost or stored in different peatlands, so that countries can meet their targets for the Paris climate accord and future agreements. And basic information about peatlands - including their extent and depth - is still lacking in many areas. Just three years ago, scientists discovered the world's largest continuous tropical peatland in the Congo basin of central Africa ${ }^{7}$.

"It is impossible to monitor greenhouse-gas emissions over such large areas directly in practice - no country in the world does that," says Joosten. In Indonesia, non-governmental organizations have highlighted that there is no independent monitoring of re-wetting effectiveness, he says.

And despite efforts to raise the water table in large swathes of Indonesia's peatlands, the country faced one of its worst fire seasons in 2019. “The areas that burnt were sites that were restored," says Lahiru Wijedasa, a peatland ecologist at the National University of Singapore who is studying Indonesia's peatlands.

\section{"At what point is peat restored? We've spent millions and haven't really thought through what success will look like."}

"We are at the early stages of understanding how these ecosystems function as a whole," he says. The fires call into question whether Indonesia's degraded peatlands can be restored and how they will respond in the future, says Wijedasa.

Andersen agrees. "If degradation is too extensive, are we at risk of losing peatland areas before we can do anything about it?"

\section{Burning questions}

On 12 May 2019, a fire broke out on one of Andersen's restoration sites in Scotland. She recalls sleepless nights spent tracking the fast-moving blaze as it burnt more than 50 square kilometres. "It looked apocalyptic with an orange sky and dark clouds of smoke," she says. "You could hardly breathe or see." But what was most impressive, she recounts, is the speed at which it travelled. "It basically covered nearly 15 kilometres in one day."

Andersen says that unusually hot, dry conditions preceded the fire and left the Sphagnum moss brittle. "The rivers were the lowest they've been since 1976." Serendipitously, a couple of the driest sites were part of the InSAR validation study. The researchers found that the surface of the peat that had been most affected by the drought had collapsed, and it hadn't recovered when it began to rain again before the fire. "We saw consequences that outlast the drought for a long period of time," she says.

Still, the restoration efforts seemed to help. Areas that had good Sphagnum cover and remained wet despite the drought had only low or medium fire damage, compared with spots that were still actively drained and had only patchy Sphagnum cover, which received the deepest burns and damage, according to Andersen.

Three weeks after the fire, she and her colleagues submitted a successful grant proposal to the UK Natural Environment Research
Council to study the impact of the blazes. The team will use ground measures, images from crewless aerial vehicles, and InSAR data to compare different types of peatland management - some had been restored more intensively, whereas others had been left to recover with fewer interventions. The researchers will assess how severely the peat burnt in each area, how it recovers and how much carbon was lost. They have also installed a fifth flux tower in the burnt area to measure how the fires affect carbon emissions. These data will be useful as researchers determine how best to restore sites to withstand future climate stresses, says Andersen.

Scotland has several advantages over other regions in its quest to restore peatlands - for example, landowners in the sparsely populated Flow Country can still make a living from restored peatlands, typically through tourism related to hunting and fishing. In Indonesia, however, people struggle to find crops that will grow on wet peaty soils and provide livelihoods for residents.

I was able to see at first hand some of the impacts of Scotland's efforts last year during a slog through the rain at the Langwell and Braemore estate. Roughly 6,000 newly installed dams have stymied erosion on grounds used for stag hunting and fishing. Between the dams, the water has pooled and is dotted with iridescent mosses. Anson MacAuslan was among the first estate managers to secure funding from Peatland Action - a project funded by the Scottish government to restore peatlands. He has spent roughly $£ 185,000$ on restoring $7 \%$ of the 19,000 -hectare estate. He has already seen direct benefits from the dams, which have reduced flooding risk and improved water quality in the streams where salmon swim.

As several of the neighbouring estates start their own restoration projects, Andersen says that the shift in public perception of peatlands has been a key legacy of the Flow Country restoration project. There is even an effort afoot to nominate the Flow Country as a United Nations Educational, Scientific and Cultural Organization (UNESCO) World Heritage sitewhich would be a first for a peatland. Although people used to call this landscape worthless, she says, "we don't hear that any more".

Virginia Gewin, a science journalist in Portland, Oregon, reported this story with support from the European Geosciences Union.

\footnotetext{
1. Turetsky, M. R. et al. Nature Geosci. 8, 11-14 (2015).

2. Hambley, G. et al. Mires Peat 23, 5 (2019).

3. Nugent, K. A. et al. Environ. Res. Lett. 14, 124030 (2019).

4. Bastin, J.-F. et al. Science 365, 76-79 (2019).

5. Alshammari, L. et al. JGR Biogeosciences https://doi. org/10.1029/2018JG004953 (2019)

6. Leifeld, J., Wüst-Galley, C. \& Page, S. Nature Clim. Change 9, 945-947 (2019).

7. Dargie, G. C. et al. Nature 542, 86-90 (2017).
} 